\title{
Hematoma and abscess formation caused by Mycoplasma hominis following cesarean section
}

This article was published in the following Dove Press journal:

International Journal of Women's Health

14 January 2011

Number of times this article has been viewed

\author{
Hisato Koshiba ${ }^{1,2}$ \\ Akemi Koshiba ${ }^{1,2}$ \\ Yasushi Daimon ${ }^{3}$ \\ Toshifumi Noguchi ${ }^{1,2}$ \\ Kazuhiro Iwasaku² \\ Jo Kitawaki ${ }^{2}$ \\ 'Department of Obstetrics and \\ Gynecology, Kyoto Prefectural \\ Yosanoumi Hospital, Kyoto, Japan; \\ ${ }^{2}$ Department of Obstetrics and \\ Gynecology, Kyoto Prefectural \\ University of Medicine, Graduate \\ School of Medical Science, Kyoto, \\ Japan; ${ }^{3}$ Department of Clinical \\ Laboratory, Kyoto Prefectural \\ Yosanoumi Hospital, Kyoto, Japan
}

Correspondence: Hisato Koshiba Department of Obstetrics and Gynecology, Kyoto Prefectural Yosanoumi Hospital, 48I Azaotokoyama, Yosano-cho, Yosa-gun, Kyoto 629-226I, Japan

Tel +8I 77246337 |

Fax +8I 772462728

Email hkoshiba@koto.kpu-m.ac.jp

\begin{abstract}
Mycoplasma species cannot be identified by routine bacteriological culture methods and are resistant to common antimicrobial agents. Mycoplasma hominis usually colonizes the lower urogenital tract and causes pyelonephritis, pelvic inflammatory disease, chorioamnionitis, rupture of fetal membranes, preterm labor, postpartum fever, postabortal fever, and neonatal infection. This organism is highly prevalent in cervicovaginal cultures of sexually active women. M. hominis, M. genitalis, Ureaplasma urealyticum, and U. parvum may invade and infect placental and fetal tissues, leading to adverse pregnancy outcomes. M. hominis occasionally causes nongenitourinary infection of the blood, wounds, central nervous system, joints, or respiratory tract. We present a case of a 27 -year-old woman who developed abdominal wound hematoma and abscess after cesarean section. The wound was drained, but her high fever persisted, in spite of antibiotic treatment using flomoxef sodium and imipenem cilastatin sodium. Because the exudate exhibited $M$. hominis growth in an anaerobic environment, we administered the quinolone ciprofloxacin. This therapy resolved her fever, and her white blood cell count and C-reactive protein level diminished to the normal ranges. To our knowledge, there are four published articles regarding the isolation of $M$. hominis from postcesarean incisions. Based on the current study and the literature, infection by this pathogen may cause hematoma formation with or without abscess after cesarean section or in immunosuppressed postoperative patients. In such cases, physicians may need to suspect Mycoplasma infection and initiate appropriate antibacterial treatment as soon as possible in order to avoid persistent fever.
\end{abstract}

Keywords: Mycoplasma hominis, cesarean section, hematoma, abscess

\section{Introduction}

Mycoplasma hominis usually colonizes the lower urogenital tract and can cause pyelonephritis, pelvic inflammatory disease, chorioamnionitis, rupture of fetal membranes, preterm labor, postpartum fever, postabortal fever, and neonatal infection. ${ }^{1-9}$ This organism is a marker for sexual activity, as demonstrated by its higher prevalence in cervicovaginal cultures of sexually active women than in those before sexual debut. M. hominis, M. genitalis, Ureaplasma urealyticum, and U. parvum may invade and infect placental and fetal tissues, leading to adverse pregnancy outcomes. ${ }^{1}$ In particular, M. hominis and U. urealyticum have been documented to cause genital tract infectious diseases for several decades. M. hominis occasionally causes nongenitourinary infection of the blood, wounds, central nervous system, joints, or respiratory tract. ${ }^{10,11}$ To our knowledge, there are four published articles regarding the isolation of this pathogen from postcesarean incisional infections. ${ }^{5,12-14}$ We present a case of $M$. hominis infection after cesarean section. This case report and the literature provide the features of postoperative infection with this organism, of which physicians should remain mindful. 


\section{Case presentation}

A 27-year-old woman, para 0 , underwent emergency cesarean section because of labor arrest and cephalopelvic disproportion at 39 weeks of gestation. A transverse skin incision was made at the lower abdomen, and the patient was delivered of an infant with meconium-stained amniotic fluid. Four $1 \mathrm{~g}$ doses of flomoxef sodium prophylaxis were administered intravenously. The first dose was infused at the start of the operation, followed by the other doses 12, 24, and 36 hours later. On postoperative day 5 , the patient developed a fever of $39.0^{\circ} \mathrm{C}$ and erythema with swelling and tenderness around the abdominal wound. Blood examination revealed a white blood cell count of $18,400 / \mathrm{mm}^{3}$ and a C-reactive protein (CRP) level of $15.4 \mathrm{mg} / \mathrm{dL}$ (Figure 1). A lower abdominal computed tomography (CT) scan revealed subcutaneous hematoma and rectus abdominis muscle abscess (Figure 2). These findings prompted us to open the central portion of her abdominal wound (approximately $2 \mathrm{~cm}$ width) under local anesthesia, for the purpose of drainage. A bloody purulent exudate was obtained from the incision, which was subjected to bacteriological culture. The Gram stain indicated numerous altered polymorphonuclear leukocytes without any pathogens (Figure 3). We irrigated the incision with $100 \mathrm{~mL}$ of saline daily and intravenously administered $1 \mathrm{~g}$ flomoxef sodium twice daily. On day 8 , an abdominal CT scan suggested that the subcutaneous hematoma and rectus abdominis muscle abscess had subsided (Figure 2), indicating that our drainage was effective. Nevertheless, her fever persisted, and the white blood cell count and CRP level

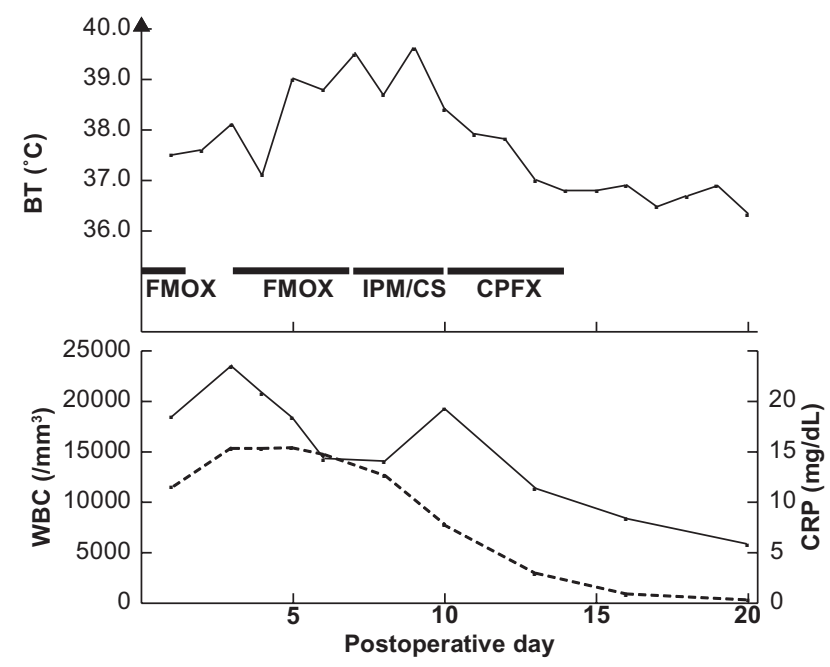

Figure I Body temperature (BT), white blood cell count (WBC), and C-reactive protein (CRP) level after cesarean section. One gram of flomoxef sodium (FMOX) twice daily, $500 \mathrm{mg}$ of imipenem cilastatin sodium (I:I; IPM/CS) twice daily, and $300 \mathrm{mg}$ of ciprofloxacin (CPFX) twice daily were administered intravenously. Solid line: WBC; broken line: CRP. CPFX chemotherapy resolved the patient's fever when WBC and CRP diminished to their normal ranges.

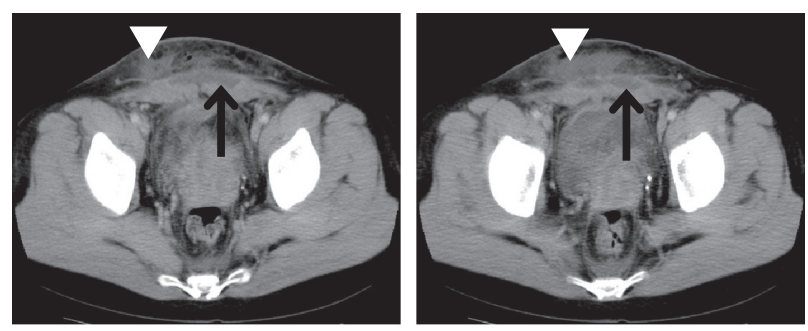

Postoperative day 5

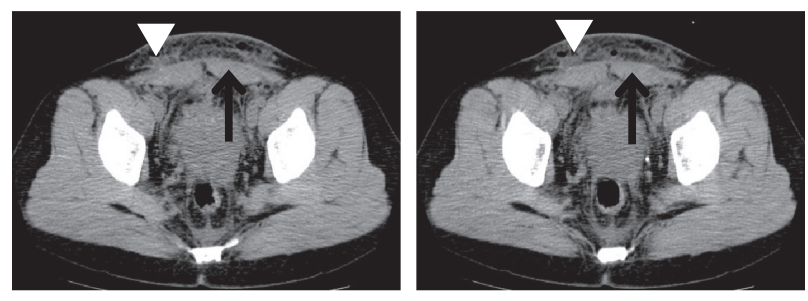

Postoperative day 8

Figure 2 Computed tomography scans. Rectus abdominis muscle abscess (arrow) and subcutaneous hematoma (arrowhead) were revealed on postoperative day 5 and had subsided on day 8 .

remained high. On day 7, we began an intravenous infusion of imipenem.cilastatin sodium $(1: 1 ; 500 \mathrm{mg})$ twice daily, instead of flomoxef sodium. On day 10, the abdominal incisional exudative fluid specimen obtained on day 5 revealed the growth of tiny colonies on a sheep blood agar culture plate under anaerobic conditions. The colonies were pinpoint sized, translucent, measuring 50-300 $\mu \mathrm{m}$ in diameter, and grew on blood agar in an anaerobic or 5\% carbon dioxide atmosphere in 2-3 days but showed no growth in an aerobic environment in subculture. On Gram stain of the colonies, the cells were so small that their cellular morphology was invisible under a routine light microscope (Figure 4). The isolate was identified as $M$. hominis based on morphology of colonies, size of cells, and culture condition, being compatible with unsuccessful chemotherapy using a $\beta$-lactam agent. Therapy with a quinolone, ciprofloxacin (300 mg twice daily), was started intravenously, and imipenem.cilastatin sodium therapy was discontinued. This antibacterial treatment, during which breastfeeding was avoided, was continued until day 14 when

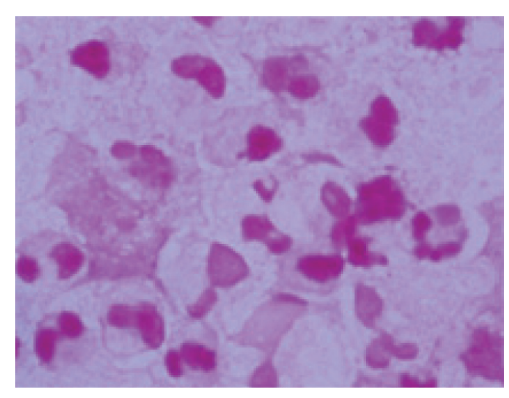

Figure $3 \mathrm{Gram}$ stain of the abdominal incisional exudate. This indicates numerous altered polymorphonuclear leukocytes without any pathogens. 


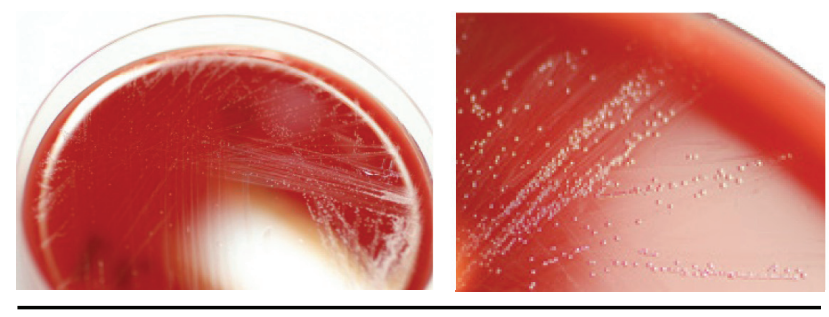

Small colonies on sheep blood agar culture plate

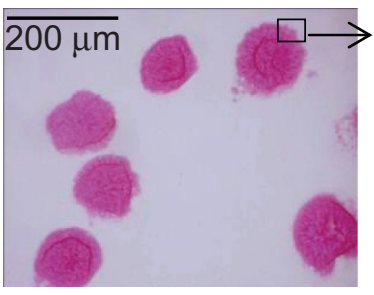

40x magnification

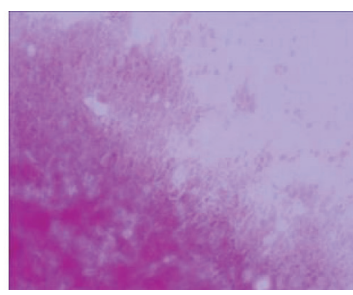

1000x magnification

Gram stain of the colonies

Figure 4 Mycoplasma hominis colonies grown in an anaerobic environment. They were pinpoint sized, translucent, and measuring 50-300 $\mu \mathrm{m}$ in diameter. Subsequently, the colonies were Gram stained to be visualized more distinctly.

her fever was resolved. The white blood cell count and CRP level diminished to their normal ranges, and the patient was discharged home 21 days after the cesarean section.

\section{Discussion}

Mycoplasma species lack a cell wall. They appear as an amorphous mass on Gram staining and are therefore unidentifiable by this method. ${ }^{9,13}$ In addition, M. hominis is a slow-growing bacterium, and its identification and antimicrobial sensitivity testing with routine culture methods are difficult. Therefore, appropriate antibacterial therapy is generally started late. Incubation in an anaerobic environment may enhance the growth of this pathogen," although 48-96 hours are usually required for its growth on nonselective routine bacteriological media. Furthermore, this organism is cultured most successfully on designed media, such as Shepard's 10B urea broth and A8 solid medium, after 24-48 hours of incubation. ${ }^{15}$ Media designed for detection of Mycoplasma are commercially available (Remel Inc., Lenexa, KS, USA). M. hominis colonies are pinpoint sized, flat, measuring $20-300 \mu \mathrm{m}$ in diameter, and have a characteristic fried-egg appearance when observed under $10 \times$ magnification. In our case, the pathogen grew under anaerobic conditions.

Mycoplasma species do not have a cell wall, which is the target of $\beta$-lactam antimicrobials that are commonly used as prophylactic agents for postsurgical infections. Erythromycins are also less effective against $M$. hominis, ${ }^{10,13}$ whereas $M$. pneumoniae is susceptible to these drugs. Tetracycline has historically been considered the antibiotic of choice for treating M. hominis infections, $, 9,16$ and clindamycin and lincomycin chloride are often used to treat infection with tetracycline-resistant strains. ${ }^{9}{ }^{10,17}$ Quinolones, including ciprofloxacin, ofloxacin, temafloxacin, sparfloxacin, trovafloxacin, gemifloxacin, gatifloxacin, moxifloxacin, and garenoxacin, are equally active against tetracyclinesusceptible as well as tetracycline-resistant strains of M. hominis. ${ }^{18-24}$ Because $M$. hominis is typically resistant to macrolides, $\beta$-lactams, aminoglycosides, vancomycin, trimethoprim, and sulfonamides, ${ }^{9,10,13,17,23,25}$ administration of effective antimicrobial agents is often initiated late.

Due to the aforementioned reasons, high fever and inflammation persist for a long time in many cases of M. hominis infection. Polymerase chain reaction (PCR) is a simpler, more rapid, and more sensitive method than culturing for the identification of this organism; therefore, a PCR assay should be performed if $M$. hominis infection is suspected. ${ }^{26}$

In our patient, abdominal wound hematoma and abscess due to M. hominis were formed following cesarean section, and drainage and the administration of a quinolone, ciprofloxacin, improved the infection. To our knowledge, there are four published articles on the isolation of this organism from postcesarean incisions in which the patients developed hematomas. ${ }^{5,12-14}$ In one patient with M. hominis wound infection after cesarean section and in three patients with $M$. hominis and $U$. urealyticum infection, aspiration of the incision yielded a cloudy serosanguinous fluid. ${ }^{12,13}$ The serosanguinous exudates suggest the presence of abdominal incisional purulent hematoma. In a case of hematoma and abscess formation due to $M$. hominis infection at the site of a uterine incision after cesarean section, drainage and administration of a quinolone, pazufloxacin mesilate, promptly resolved the patient's fever. ${ }^{14}$ A perihepatic hematoma with $M$. hominis was observed after a liver transplant, ${ }^{27}$ and a perinephric hematoma was infected with this pathogen after a renal transplant. ${ }^{28}$ Moreover, hematoma infection with this bacterium developed following transplant nephrectomy. ${ }^{29}$ These indicate that $M$. hominis infections after surgery may cause hematoma formation in immunosuppressed patients. When a hematoma with bacterial infection or an abscess presents, drainage, aspiration, and debridement are promising treatments. Physicians may need to subject the specimens to bacteriological culture in an anaerobic environment, on designed media, or with PCR assay, to initiate appropriate antibacterial therapy as soon as possible if the causative organism is Mycoplasma. 
The route of wound infection by $M$. hominis in this case is unknown. One possible speculation is that the pathogen invaded and infected fetal membranes and amniotic fluid from the vagina or uterine cervix during pregnancy, resulting in postcesarean infection.

\section{Conclusion}

We present a case of abdominal wound infection by M. hominis following cesarean section. Based on our observation, this pathogen may cause hematoma formation with or without abscess after cesarean section or in immunosuppressed postoperative patients. In such cases, physicians may need to suspect Mycoplasma infection and start effective antimicrobial treatment as soon as possible in order to avoid persistent fever.

\section{Disclosure}

The authors report no conflicts of interest in this work.

\section{References}

1. Larsen B, Hwang J. Mycoplasma, Ureaplasma, and adverse pregnancy outcomes: a fresh look. Infect Dis Obstet Gynecol. Epub 2010 Jul 12.

2. Stokes EJ. Human infection with pleuropneumonia-like organisms. Lancet. 1995;268:276-279.

3. Jones DM. Mycoplasma hominis in abortion. Br Med J. 1967;1: 338-340.

4. Tully JG, Smith LG. Postpartum septicemia with Mycoplasma hominis. JAMA. 1968;204:827-828.

5. Russell FE, Fallon RJ. Mycoplasma and the urogenital tract. Lancet. 1970;1:1295.

6. Di Musto JC, Bohjalian O, Millar M. Mycoplasma hominis type I infection and pregnancy. Obstet Gynecolo. 1973;41:33-37.

7. Wealthall SR. Mycoplasma meningitis in infants with spina bifida. Dev Med Child Neurol Suppl. 1975;35:117-122.

8. Berman SM, Harrison HR, Boyce WT, Haffner WJ, Lewis M, Arthur JB. Low birth weight, prematurity, and postpartum endometritis: association with prenatal cervical Mycoplasma hominis and Chlamydia trachomatis infections. JAMA. 1987;257:1189-1194.

9. Taylor-Robinson D. Ureaplasma urealyticum and Mycoplasma hominis. In: Mandell GL, Bennett JE, Dolin R, editors. Principles and Practice of Infectious Diseases. New York: Churchill Livingstone; 1995: 1713-1717.

10. Madoff S, Hooper DC. Nongenitourinary infections caused by Mycoplasma hominis in adults. Rev Infect Dis. 1988;10:602-613.

11. McMahon DK, Dummer JS, Pasculle AW, Cassell G. Extragenital Mycoplasma hominis in adults. Am J Med. 1990;89:275-281.

12. Phillips LE, Faro S, Pokorny SF, Whiteman PA, Goodrich KH, Turner RM. Postcesarean wound infection by Mycoplasma hominis in a patient with persistent postpartum fever. Diagn Microbiol Infect Dis. 1987;7:193-197.
13. Maccato M, Faro S, Summers KL. Wound infections after cesarean section with Mycoplasma hominis and Ureaplasma urealyticum. A report of three cases. Diagn Microbiol Infect Dis. 1990;13:363-365.

14. Yamaguchi M, Kikuchi A, Ohkusu K, et al. Abscess formation due to Mycoplasma hominis infection after cesarean section. J Obstet Gynaecol Res. 2009;35:593-596.

15. Waites KB, Bébéar C, Robertson JA, Cassell GH. Laboratory diagnosis of mycoplasmal and ureaplasmal infections. Clin Microbiol Newslett. 1996;18:105-112.

16. Myhre EB, Mårdh PA. Treatment of extragenital infections caused by Mycoplasma hominis. Sex Transm Dis. 1983;10(4 Suppl):382-385.

17. Bygdeman SM, Mårdh PA. Antimicrobial susceptibility and susceptibility testing of Mycoplasma hominis: a review. Sex Transm Dis. 1983; 10(4 Suppl):366-370.

18. Kenny GE, Hooton TM, Roberts MC, Cartwright FD, Hoyt J. Susceptibilities of genital mycoplasmas to the newer quinolones as determined by the agar dilution method. Antimicrob Agents Chemother. 1989;33:103-107.

19. Segreti J. In vitro activity of temafloxacin against pathogens causing sexually transmitted diseases. Am J Med. 1991;91:24S-26S.

20. Lefèvre JC, Bauriaud R, Gaubert E, Escaffre MC, Lareng MB. In vitro activity of sparfloxacin and other antimicrobial agents against genital pathogens. Chemotherapy. 1992;38:303-307.

21. Kenny GE, Cartwright FD. Susceptibilities of Mycoplasma pneumoniae, Mycoplasma hominis, and Ureaplasma urealyticum to a new quinolone, trovafloxacin (CP-99, 219). Antimicrob Agents Chemother. 1996;40: 1048-1049.

22. Duffy LB, Crabb D, Searcey K, Kempf MC. Comparative potency of gemifloxacin, new quinolones, macrolides, tetracycline and clindamycin against Mycoplasma spp. J Antimicrob Chemother. 2000;45(Suppl 1): 29-33.

23. Kenny GE, Cartwright FD. Susceptibilities of Mycoplasma hominis, M. pneumoniae, and Ureaplasma urealyticum to GAR-936, dalfopristin, dirithromycin, evernimicin, gatifloxacin, linezolid, moxifloxacin, quinupristin-dalfopristin, and telithromycin compared to their susceptibilities to reference macrolides, tetracyclines, and quinolones. Antimicrob Agents Chemother. 2001;45:2604-2608.

24. Waites KB, Crabb DM, Bing X, Duffy LB. In vitro susceptibilities to and bactericidal activities of garenoxacin (BMS-284756) and other antimicrobial agents against human mycoplasmas and ureaplasmas. Antimicrob Agents Chemother. 2003;47:161-165.

25. Braun P, Klein JO, Kass EH. Susceptibility of genital mycoplasmas to antimicrobial agents. Appl Microbiol. 1970;19:62-70.

26. Petrikkos GL, Hadjisoteriou M, Daikos GL. PCR versus culture in the detection of vaginal Ureaplasma urealyticum and Mycoplasma hominis. Int J Gynaecol Obstet. 2007;97:202-203.

27. Jacobs F, van de Stadt J, Gelin M, et al. Mycoplasma hominis infection of perihepatic hematomas in a liver transplant recipient. Surgery. 1992; 111:98-100.

28. Orange GV, Jones M, Henderson IS. Wound and perinephric haematomata infection with Mycoplasma hominis in a renal transplant recipient. Nephrol Dial Transplant. 1993;8:1395-1396.

29. Legg JM, Titus TT, Chambers I, Wilkinson R, Koerner RJ, Gould FK. Hematoma infection with Mycoplasma hominis following transplant nephrectomy. Clin Microbiol Infect. 2000;6:619-621.
International Journal of Women's Health

\section{Publish your work in this journal}

The International Journal of Women's Health is an international, peerreviewed open-access journal publishing original research, reports, reviews and commentaries on all aspects of women's healthcare including gynecology, obstetrics, and breast cancer. Subject areas include: Chronic conditions (migraine headaches, arthritis, osteoporosis);

\section{Dovepress}

Endocrine and autoimmune syndromes; Sexual and reproductive health; Psychological and psychosocial conditions. The manuscript management system is completely online and includes a very quick and fair peer-review system. Visit http://www.dovepress.com/ testimonials.php to read real quotes from published authors. 